Article

\title{
Estimating the Number of Agricultural Fatal Injuries Prevented by Agricultural Engineering Developments in the United States
}

\author{
Salah F. Issa *, Kiana Patrick, Steven Thomson and Bradley Rein \\ U.S. Department of Agriculture, National Institute of Food and Agriculture, Washington, DC 20024, USA; \\ kianapatrick@csu.fullerton.edu (K.P.); steven.j.thomson@usda.gov (S.T.); brein@usda.gov (B.R.) \\ * Correspondence: salahfuadissa@hotmail.com
}

Received: 7 August 2019; Accepted: 23 September 2019; Published: 25 September 2019

\begin{abstract}
Agriculture has been consistently marked as one of the deadliest industries by the United States Bureau of Labor Statistics (BLS). While this statistic is widely used in promoting agricultural safety and health, it does not paint a complete picture on the current status of agricultural safety and the advances that have been made in the last century. For example, even with a stagnant rate of injury, the BLS has reported that fatal incidents decreased from a high of 855 incidents in 1993 to a low of 500 incidents in 2013. The purpose of this study was to analyze the impact that agricultural engineering developments had on reducing fatal injuries. Agricultural engineering developments are defined as any agricultural improvement that results in a direct reduction in the amount of labor needed. This study uses existing federal agricultural statistical, injury and demographic data to calculate the impact that engineering, in contrast to yield improvements and safety enhancements, contributed to a reduction in the number of fatal incidents. The study found that engineering developments could have contributed to the reduction in the number of fatal injuries by about 170 incidents from 1992 to 2015 . This represents $63 \%$ of the total reduction in the number of fatal injuries. In conclusion, agricultural engineering developments play a substantial role in reducing the number of fatal incidents by removing and reducing labor exposure to hazardous environments.
\end{abstract}

Keywords: agricultural safety; injury prevention; fatal injuries; engineering; fatal injury rates; labor efficiency; agricultural productivity; agricultural engineering

\section{Introduction}

Agriculture is considered to be one of the most dangerous industries in the United States (US) [1,2]. In addition, the overall fatal injury rate reported by the Bureau of Labor Statistics (BLS) has remained fairly constant over the last thirty years $[3,4]$ in spite of tremendous efforts in safety training [5-7] and safety improvements to agricultural equipment [8-10]. Indeed, due to the massive transformation that has occurred in agriculture [11,12], injury rates fail to capture a complete picture regarding the agricultural safety landscape. This can be most clearly seen when reviewing the number of fatal injuries over time that have occurred each year from 1992 to the present. From 1992 to 1994, an average of 834 deaths each year was reported in the agricultural industry. By 2000, this number dropped to 720 deaths, and in the last three years of reporting (2015-2017), this has averaged 581 incidents per year [4]. This represents a 30\% drop in a 25 year period. The decreased number of fatal injuries could be a symptom of the transformation of agriculture in the last 60-70 years, in which the overall land harvested and the number of agricultural workers has decreased while production has significantly increased [11,13]. A question arises on whether the reduction in total fatal injuries can be distilled to engineering developments (e.g., better tractors), yield improvements (e.g., better genetics for animals 
and crops), or safety enhancements (e.g., safer equipment, more training, or better enforcement). The purpose of this paper is to analyze existing federal datasets and make a preliminary delineation on the contribution that engineering development has in the reduction in total fatal injuries for the US in comparison to yield improvements and safety enhancements.

\section{Literature Review}

Fatal injuries and exposure to occupational hazards in the agricultural industry can impact those operating farms and those simply living on them, including adults, children, adolescents, and the elderly. Most adult incidents occur with males from ages 19-65 while operating motor vehicles-most commonly tractors [14]. The tractor is known as the single largest source for cause of death resulting in pelvic fractures, head/spinal cord injury, and blunt chest trauma [15,16]. Similarly, for children, $25 \%$ of the fatal incidents involved machinery, $17 \%$ involved motor vehicles, and $16 \%$ were due to drownings [17]. There is a reported child fatality about every three days, as more than half $(51 \%)$ of youth farm residents assist with operations [16]. The elderly still involved in farm operations are also commonly injured, with falls reported as a frequent occurrence [14]. These unique incident demographics highlight the unique challenges that face the field of agricultural safety. It is important to highlight the significant advancements in safety enhancements that occurred in the last 30-40 years including in areas of education, engineering (standards), and enforcement (regulation). In addition, it is important to highlight the transformation that occurred in agriculture in the last 30-40 years.

\subsection{Education and Training Programs}

In response to the lack of safety within the agricultural industry, there has been a wave of educational and training programs emerging from federal agencies, universities, professional societies, and non-profits providing assistance to farm workers and their families, agricultural health professionals, and surrounding industries impacted by agriculture.

The United States Department of Agriculture (USDA) was instrumental in establishing the AgrAbility program in 1980s that assists disabled farmers and North Central Education/Extension Research Activity 197 (NCERA 197) in 2000, a five year multi-state project focused on the collaboration between farmers and the land grant system to reduce the occupational injury and illness risk among farm workers [9]. The National Institute of Occupational Safety and Health (NIOSH) incorporated aspects of the NCERA 197 agenda in their national research plan. To further assist the programs and address some of the priority areas of the plan, NIOSH began utilizing extramural grants to fund ten agricultural disease and injury research centers around the country [9]. In addition, a youth focused center, the National Children's Center for Rural and Agricultural Health and Safety, was implemented to reduce the amount of children exposed to hazards associated with farm work [16]. Of equal importance is that NIOSH focused on funding state surveillance for diseases and injuries to further develop model population-based programs and led to the establishment of the National Agricultural Safety Database [18]. Similarly, the EPA has played a significant role in the control and education of pesticides and other environmentally hazardous agricultural exposures [19].

Lastly, university programs, professional societies and non-profits have contributed to research, education and training programs to enhance farm safety. Purdue University Agricultural Safety and Health Program contributed many curriculum programs such as "Gearing Up for Safety," an instructional resource designed to teach 14-15-year-olds about hazards on the farm [20]. Similarly, the Ohio State University extension program designed a list of agricultural safety factsheets [21]. More recently, the USDA National Institute of Food and Agriculture (NIFA) funded the Safety in Agriculture for Youth (SAY) project to maintain a clearinghouse for agricultural and safety curriculum with project led by the University of Nebraska Medical Center [22]. The American Society of Agricultural and Biological Engineers (ASABE) began the Journal of Agricultural Safety and Health (JASH), which provides a forum for the identification and discussion of safety and health issues [23]. Both the International Society for Agricultural Safety and Health (ISASH) and the National Education Center for 
Agricultural Safety have created a similar space in the form of professional improvement seminars and courses highlighting hazardous materials, respiratory protection, cardiopulmonary resuscitation (CPR), rollover protective structure (ROPS) retrofit, tractor certification, confined spaces, rescue procedures, and youth programs $[24,25]$. Similarly, non-profits have played a significant role in farm safety such as the Progressive Agriculture Foundation that runs the Progressive Agriculture Safety Day, which promotes increased safety knowledge with the aim of reducing risky behavior amongst children ages 8-13 [5]. In addition, Farm Safety 4 Just Kids had a significant impact in highlighting dangers of grain transport vehicles (GTVs), developing safety decals for GTVs and assisting in the dissemination of these decals and educational material on the dangers of GTVs [7].

\subsection{Regulations}

There are many regulations that cover various aspects of health and safety within the agricultural industry. They are set forth by the Occupational Safety and Health Administration (OSHA), the Consumer Product Safety Commission, the Environmental Protection Agency (EPA), and the Department of Labor (DOL). The OSHA general duty clause requires employers to furnish each employee with employment and a workplace free from recognized hazards causing or likely to cause death or serious harm [26]. However, this regulation does not apply to small farms (less than 10 employees) or their immediate family members. In addition, the OSHA has published more specific standards relating to various aspects of agriculture including ROPS requirements for tractors [27], agricultural confined space safety [28], cotton ginning safety [27], the use of forestry equipment [29], farm/grounds landscaping equipment [30], and power lawn mowers [31]. In addition, the EPA has two standards relating to agriculture, both pertaining to proper pesticide use: The Worker Protection Standard and the Certification of Pesticide Applicators Standard [32].

Other federal standards have been put in place regarding youth labor and migrant labor. The DOL has promulgated a standard generalizing the minimum age for child labor at 18 . The standard prohibits a child below the age of 16 from being employed in hazardous occupations with an exemption in place for family members [32]. In addition, the Migrant and Seasonal Agricultural Worker Protection Act of 1983 provided the DOL with the responsibility of ensuring that migrant and seasonal farmworkers have safe working conditions [32]. All of these standards help inform farm employers on how to be in compliance with the labor laws or farm employees about the proper use of machinery to ensure work in a safe environment.

\subsection{Standards}

There have been several engineering and safety standards implemented to accompany the educational programs and federal regulations passed. These include standards for agricultural field equipment [33], farmstead equipment [34], guarding for agricultural equipment [35,36], wording and formatting of safety signs on equipment [37], and design, testing and performance requirements for ROPS and overhead protection [38-41]. In addition, there are standards focused on describing the proper utilization of certain farm machinery such as agricultural front-end loaders [42] and safety for portable agricultural auger conveying equipment [43]. Most recently, ASABE published a grain bin access standard to enhance protection for those who enter grain bins [44].

\subsection{Agricultural Transformation}

The transformation of the agricultural industry has led to an increased intensification of production through genetic manipulation, mechanization, and information systems. The adoption of plant hybrids has sped up the mechanization of farming [11]. Similarly, the development and implementation of technologies such as artificial insemination has been critical in increasing production efficiencies. For example, artificial insemination is directly responsible for the rapid yield increases seen in milk production [11]. In addition, mechanization has also enhanced the fertilization, tillage, and irrigation of the industry, thus changing the crop environment [11]. The next technological breakthrough was 
in information systems, and these breakthroughs allow farmers to manage complex agricultural production systems and further increase production efficiency [12]. One particular type of technology expected to play a significant role is automated detection systems such as remote sensing, aerial spraying, and real time image processing. For example, remote sensing will promote production by providing up-to date imagery data for crop diseases and insect pests at different spatial, spectral, and temporal resolutions [12]. Aerial spraying allows for the rapid response of chemical pesticides sprayed in the event of a pest outbreak. The application of pesticides can even be directed with variable rate technology which will allow farmers to apply pesticide in the infected areas only, thus reducing potential environmental impact and input cost [12].

The progress made in training, regulations, engineering and the subsequent agricultural transformation highlight the importance in understanding the role that engineering development, yield improvements and safety enhancements contribute towards reducing agricultural fatalities.

\section{Materials and Methods}

Four datasets are needed to investigate the role that engineering developments, yield improvements and safety enhancements have played in the reduction of the total number of fatal injuries. The datasets are those of the yearly fatal injuries, labor data set (to estimate exposure), land harvested, and agricultural production outputs. Together, these datasets can be used to calculate labor efficiency (number of workers or hours/number of land harvested), productivity (production output/number of land harvested), and injury rates (number of injuries/number of workers or hours), with each metric representing the progress in engineering developments, yield improvements, and safety enhancements, respectively. For this preliminary analysis, it was decided that only federal datasets would be considered. There were multiple options in choosing federal datasets, with each dataset having its unique strengths and weaknesses, including:

(1) The USDA National Agricultural Statistical Services (NASS) reports production output for many crops and animal products. In addition, it reports cash receipts for farms in their census survey (usually every five years), with 1997 as the earliest year available in NASS Quick Stats [45].

(2) The USDA NASS (and NASS predecessors such as the Agricultural Statistics Board) has published a quarterly report on Farm labor since the 1930s on the number of hired laborers, including distinctions between full-time and part-time workers [46].

(3) The USDA NASS (and NASS predecessors) has published a yearly report on farm and land in farms since the 1960s on the number of farms, farmland and farm size in acres ( 1 acre $=0.405$ hectare) [47].

(4) The Bureau of Labor Statistics (BLS) publishes the Census of Fatal Occupational Injuries that reports the total fatal injuries, fatal injury rates and the number of workers for agriculture as an industry and occupation [4].

(5) The USDA Economic Research Services (ERS) publishes productivity tables that include values for production, labor and land in dollar figures accounting for inflation. There is no access to the metadata that generated these tables [13].

One of the advantages of using the USDA ERS datasets, compared with the USDA NASS or the BLS employment data, is that they include values for production, labor and land in one dataset with data going back to 1950s. Since this analysis compared labor, land, and production values, there was benefit in having all data available in one dataset with comparable values. The land and labor variables were adjusted to include labor and land quality in addition to quantity [48]. In addition, having yearly production reports in dollars was a plus and a more robust method when conducting an analysis on agriculture as a sector. Similarly, utilizing the same units across the analysis added robustness to this analysis. Lastly, a comparison between the USDA ERS and the USDA NASS showed that values for labor and land produce similar trends (Figure 1), providing support for the use of USDA ERS land and labor values. The correlation values for the ERS and the NASS land and labor datasets were $\mathrm{R}^{2}=0.96$ and 0.73 , respectively, with intercept set to zero. Both values indicated high correlation, especially 
considering that the NASS's hired labor dataset does not take farm labor into account and treats full-time and part-time workers equally. While BLS datasets represent the most comprehensive data on injury rates in agriculture, the dataset switched their method of calculating agricultural labor in 2003 and readjusted again in 2007, leading to questions on the robustness of the injury rates [4]. Therefore, the USDA ERS dataset was used for labor, land and production values, and the BLS data were used only for total fatal injuries. The BLS reported data on agricultural fatal injuries by industry were chosen over agricultural fatal injuries by occupation since they represent the whole agricultural sector, similar to the ERS values. The BLS groups the agricultural, fishing, logging and hunting industries together when reporting fatal injuries by industry. This was the value that was used in this research article.

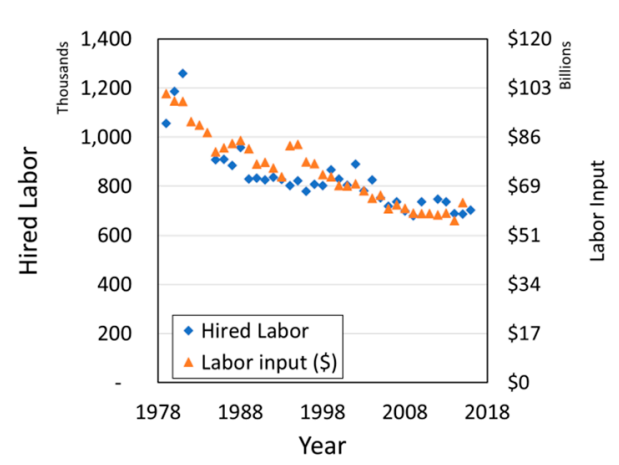

(a)

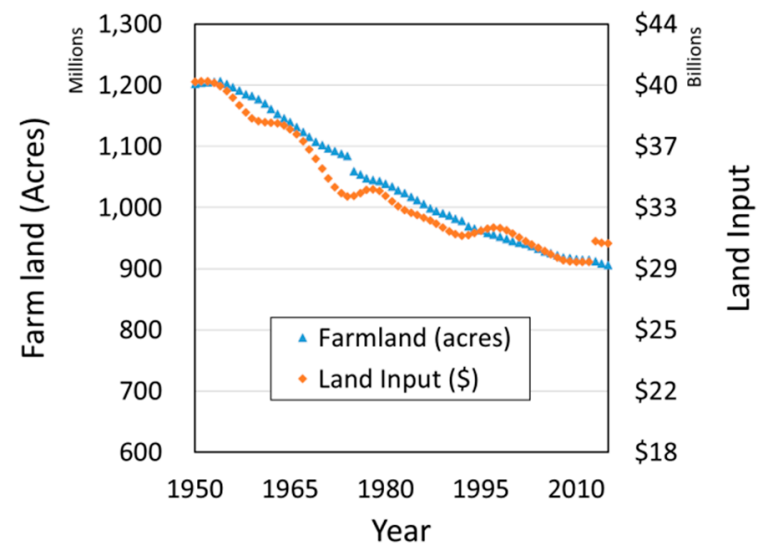

(b)

Figure 1. Comparison between The United States Department of Agriculture Economic Research Services (USDA) ERS and the USDA National Agricultural Statistical Services (NASS) data for: (a) Labor in which USDA NASS data are the number of hired laborers (both part-time and fulltime) and USDA ERS labor input is in 2005 \$ value, and (b) land values in which the USDA NASS data are the number of farm acres ( 1 acre $=0.405$ hectare) and the USDA ERS land input is in 2005 \$ value.

\section{Data Analysis}

There were three important parameters necessary to conduct this analysis: Productivity, labor efficiency and injury rates. Generally, productivity can be defined as the output/acre of land, labor efficiency as the labor used/acre of land, and injury rate as the number of injuries divided by total labor. Since, this analysis used ERS datasets, each of these parameters using ERS variables were calculated as follows:

$$
\begin{gathered}
\text { Productivity }(P R D)=\frac{\text { Agricultural Output }(\$)}{\text { Land Input }(\$)} \\
\text { Labor Efficiency }(E F F)=\frac{\text { Labor Input }(\$)}{\text { Land Input }(\$)} \\
\text { Fatal Injury Rate }(I N J)=\frac{\text { Fatal Injuries }}{\text { Labor Input }(\$)}
\end{gathered}
$$

The number of fatal injuries in a given year $(x)$ is, by definition, a function of total harvested lands, labor efficiency (how much labor is needed to cultivate those lands) and injury rate. Using Equations (1)-(3), the equation is as follows:

$$
\text { Fatal Injuries }_{x}=\text { Land Input }_{x} \times E F F_{x} \times I N J_{x}
$$

In theory, the above equation indicates that the number of injuries occurring in a given year is a reflection of productivity (since the number of acres needed is dependent on agricultural productivity), 
efficiency, and the risk of injury. Moreover, each of these parameters reflects an aspect of the agricultural transformation. Productivity reflects technological improvements such as better genetics for crops or animals resulting in higher yields. Efficiency represents engineering improvements such as no-till harvesting or more effective tractors that can process a field more efficiently and reduce the time in the field. The risk of injury represents the focus on increasing safety through engineering, education or regulation/standard enforcement. By treating each of these parameters as independent of each other, one can estimate the role each one had in reducing fatal injuries using the following equations:

$$
\begin{aligned}
P R D \text { Impact } & =\Delta \text { Land Input } \times \overline{E F F} \times \overline{I N J} \\
E F F \text { Impact } & =\overline{\text { Land Input }} \times \Delta E F F \times \overline{I N J} \\
\text { INJ Impact } & =\overline{\text { Land Input }} \times \overline{E F F} \times \Delta I N J
\end{aligned}
$$

To minimize any compounding impact the parameters might have on each other in calculating each parameter's role in reducing the number of fatal injuries, each parameter's impact was calculated on a yearly basis and then added together to generate each parameter's impact on fatal injuries. Another issue of concern is the natural yearly variance in the number of injuries that might severely skew the results based on the start or finish point. To reduce such an impact, a 5 year running average was calculated for each of the parameters (Land Input, EFF, INJ) before calculating the impact each of the three (PRD, EFF, INJ) had on the number of fatal injuries. The impact of this decision was also calculated. Another interesting parameter to calculate was the total number of fatal injuries prevented from beginning of the study due to each of these parameters. This was calculated by adding all previous year's impacts to a given year and then summing the values for all years.

Lastly, it important to note that the reduction in the number of acres was estimated to be the impact of productivity. On its own this result is incomplete, as increasing productivity not only reduces the acres harvested but also eliminates the need to expand agriculture to new lands to meet demand. The number of lives saved due to removing the need to expand agricultural lands can be considered as the potential fatal injury savings. The use of the term potential was because if productivity did not increase, agricultural fields would not have completely expanded to meet current supply requirements due to economic and land constraints. The potential savings could be calculated as follows:

$$
\text { PRD Impact } \text { potential }=\frac{\Delta \text { Agricultural Output }}{P R D_{y}} \times E F F_{x} \times I N J_{x}
$$

where $y$ and $x$ are the initial and final years, respectively.

\section{Results}

The agricultural transformation that occurred in the last six decades can easily be seen have to improved values for labor efficiency and productivity (Figure 2a). Labor efficiency improved dramatically from 1950s to 1970s, and it has continued to gradually improve since then. Productivity has also increased dramatically and was able to maintain a rapid increase until the late 2000s, when the values plateaued. Between 1992 and 2015, labor efficiency improved by $20 \%$, productivity increased by $30 \%$, and injury rates decreased by $18 \%$ (Figure 2 ). The low $\mathrm{R}^{2}$ for INJ values over time highlight the variability in year-to-year injury rates. This is expected due to inherent randomness of year-to-year injury data, yet the most important part of Figure $2 b$ is the clear trend for injury rates over time. 


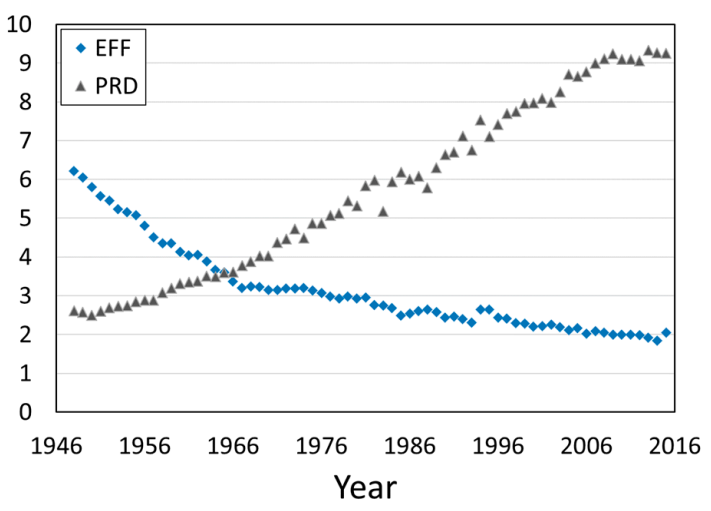

(a)

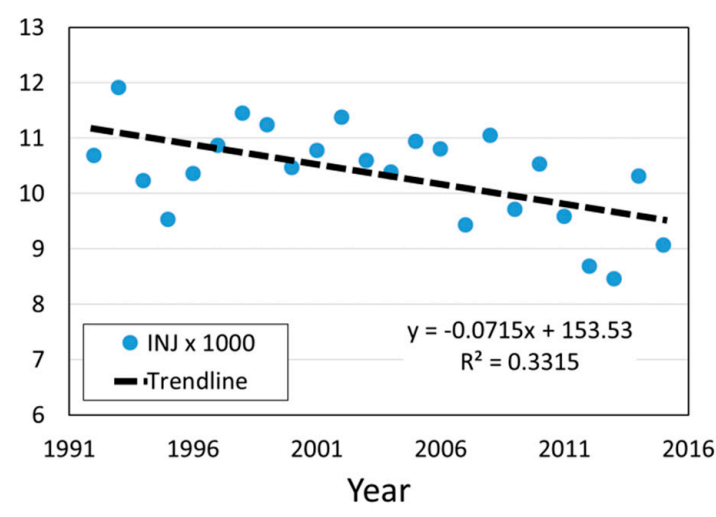

(b)

Figure 2. Calculated values from USDA ERS productivity table and the Bureau of Labor Statistics (BLS) injury data displayed overtime for (a) labor efficiency $(E F F)$, productivity $(P R D)$, and (b) fatal injury rate (INJ). EFF was calculated as labor input (\$) divided by land input (\$). PRD was calculated as the agricultural output $(\$)$ divided by land input $(\$)$. INJ $\times 1000$ was calculated as the number of fatal injuries divided by labor input (\$) and multiplied by 1000 .

The total number of fatal injuries from 1996 to 2015, based on a five-year moving average, decreased by 273 fatalities (Figure 3). The decreased need for labor (labor efficiency) was the main cause in reduction of fatalities, with 172 attributed to it, followed by reduction in injury risk (76 incidents), and productivity increases (27 incidents). In addition, another 121 potential fatal injury savings could be attributed to increases in productivity. From a cumulative perspective, the reduction in injury rates over 1996-2015 timespan saved a total of 540 lives, of which 347 could be attributed to a gain in labor efficiencies, 134 to reduced injury rates, and 59 to increased productivity.

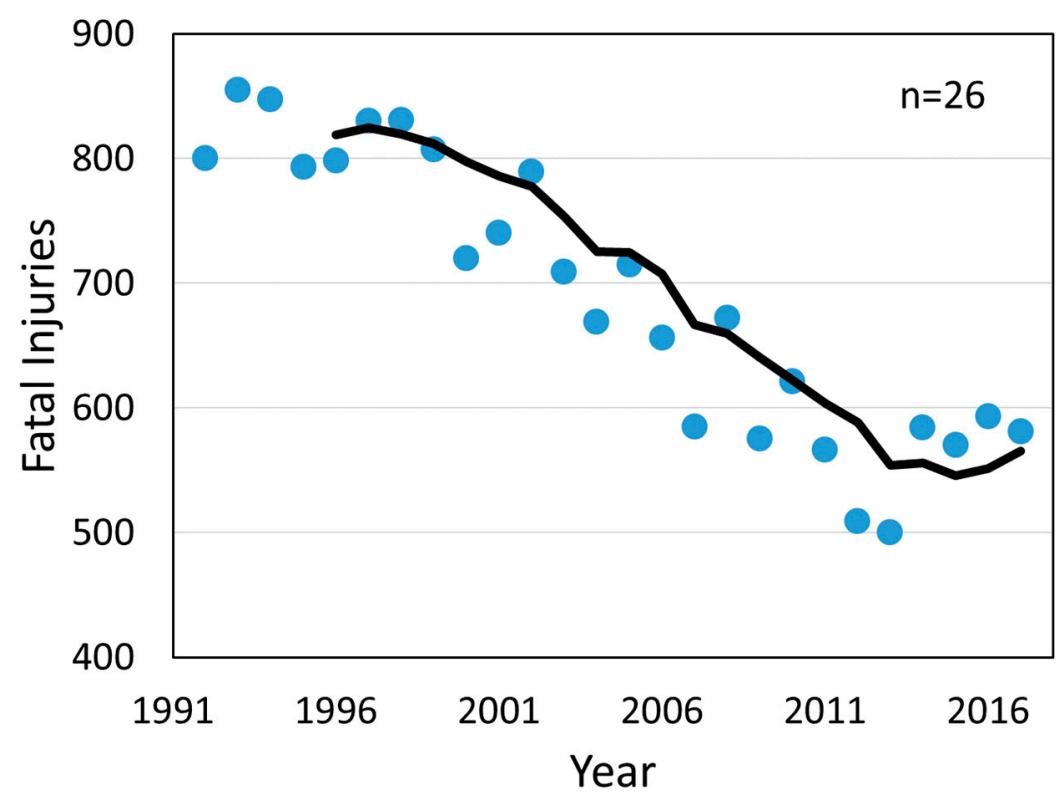

Figure 3. The actual number of fatal injuries per year for the agricultural industry (BLS) with a five year running average (black line).

\section{Discussion}

Decreased labor need, which could be mainly attributed to developments in engineering designs and technologies, was the primary factor in the reduction in the number of fatalities in the agricultural industry. This result is not surprising, since the BLS reported similar injury rates for the period 
1992-1996 and 2013-2017 (23.64 vs. 23.56 fatal injuries/100,000, respectively) [3,4]. More surprising is the fact that $28 \%$ of the reduction in fatal injuries could still be attributed to a reduction in injury risk rate (INJ). This contribution could be attributed to safety enhancements in safer engineering designs, curriculum and education efforts, improved agricultural standards, and regulation enforcement. An example of a safety enhancement that incorporate all three E's (engineering, education and enforcement) is designing grain bins that can support anchor points, training workers on how to use harnesses, and enforcing regulations/standards on harness use in grain bins. Lastly, it is surprising that even when accounting for potential lives saved, labor efficiency (EFF) contributed more towards reducing injuries than productivity improvements.

This analysis opens up a wide variety of follow up studies that could be conducted. Primarily, running this analysis on state level, focusing it on particular specialties (such as field crops), or a combination of both might lead to more specific insights on the impact of the various safety enhancements have on injury rates. Focusing on a specific industry where improvements are well known might allow for the quantification of the impact each of these improvements has had on the field. For example, Myers and Hendricks [49] reported that tractor overturn fatality rates decreased by $28.5 \%$ between 1992 and 2007, while the overall fatality rate reported by the BLS increased by $20.6 \%$. Understanding the shift in injury rates and the contributing factors (engineering, productivity, or safety) in reducing tractor overturns could provide insight on the effectiveness of safety programs. Another interesting study would be to run this analysis on non-fatal injuries. Lastly, conducting this analysis on other complete data sources could confirm the resulting conclusions.

\section{Limitations}

It is important to note that a major simplification of this analysis was ignoring the connectivity between productivity, efficiency and risk. Many agricultural scenarios tend to improve one or two of these parameters at the expense of another. For example:

(1) One of the most important safety recommendations when entering grain storage facilities is having an observer that can assist in making sure harness lines are taunt and call for help if needed [50]. For farmers to follow this recommendation, they can significantly reduce their risk of grain entrapment, but they do so at the risk of reducing their efficiency by having two individuals instead of one empty the grain bins.

(2) A farmer deciding to plant a cover crop could potentially increase yield (by maintaining soil quality), but this would be at the expense of efficiency due to increased labor demands.

(3) Banning the use of a highly effective pesticide due to potential health risk would decrease injury rates but also potentially reduce productivity.

(4) Utilizing and adopting all-terrain vehicles (ATV) has increased farmer efficiency but at the expense of an increased risk of injury.

Unless an analysis compares the impact of introducing a specific technology on these parameters, it might not be possible to further separate these parameters. Ignoring the potential connectivity does appear to be the correct approach when conducting an analysis on the overall agricultural industry.

Another potential limitation is data. It was reported that U.S. government non-fatal occupational injuries tend to be underreported [51], and, due to OSHA limited farm regulations, there is a concern that the number of fatal injuries are underreported. Similarly, using the $\$$ values for labor and land instead actual values could have also introduced errors in the data. However, if the error in input data was constant and independent of time, then the errors did not impact the conclusions of this study, since this analysis focused on the difference between values and not the absolute values.

\section{Conclusions}

In conclusion, it is possible to measure the role that engineering developments, yield improvements and safety enhancements play in reducing overall fatal injury levels. It was found that engineering 
developments were the largest contributor $(63 \%)$ to reducing the number of fatal injuries during the time period of 1992-2015. In addition, this paper provides the necessary tools and equations to measure the role that each of the components above contribute in reducing injury levels. These tools could be utilized in a variety of settings or industries. This article introduces a paradigm shift on how agricultural safety is viewed by pushing for a bigger picture approach in understanding the impact that engineering and other technological improvements have had in reducing the number of injuries. It also potentially leads to interesting ethical concerns that safety professionals would need to study. If a technology increases injury risk but also increases productivity and efficiency, should it be adopted if it would reduce the total number of fatalities (due to savings in the number of laborers needed)? What if the technology was neutral in terms of safety or had a negative impact on the number of fatalities? Is there a point in which increased productivity is worth the potential increase in the number of injuries?

Author Contributions: Conceptualization, S.F.I. and B.R.; data curation, S.F.I. and K.P.; formal analysis, S.F.I.; investigation, S.F.I.; methodology, S.F.I.; supervision, S.T. and B.R.; validation, S.F.I., S.T. and B.R.; visualization, S.F.I.; writing—original draft, S.F.I. and K.P.; writing—review \& editing, S.T. and B.R.

Funding: This research received no external funding.

Acknowledgments: This activity was supported by an AAAS Science \& Technology Policy Fellowship served at U.S. Department of Agriculture National Institute of Food and Agriculture. Any opinions, findings, conclusions, or recommendations expressed in this publication are those of the author(s) and do not necessarily reflect the view of the U.S. Department of Agriculture or the American Association for the Advancement of Science. Special thanks to Robbin Shoemaker (USDA-NIFA) for providing input on data. Special thanks to Sun Ling Wang (ERS) for assisting with ERS data tables. Special thanks to Parag Chitnis for providing mentorship and encouragement for this project.

Conflicts of Interest: The authors declare no conflict of interest.

\section{References}

1. Evans, J.; Heiberger, S. Agricultural media of coverage of farm safety: Review of the literature. J. Agromed. 2016, 21, 91-105. [CrossRef] [PubMed]

2. Jadhav, R.; Achutan, C.; Haynatzki, G.; Rajaram, S.; Rautiainen, R. Risk factors for agricultural injury: A systematic review and meta-analysis. J. Agromed. 2015, 20, 434-449. [CrossRef] [PubMed]

3. Census of Fatal Occupational Injuries (CFOI). Current and Revised Data. Available online: https://www.bls. gov/iif/oshcfoil.htm (accessed on 6 August 2019).

4. Census of Fatal Occupational Injuries. Archived Data. Available online: https://www.bls.gov/iif/ oshcfoiarchive.htm\#rates (accessed on 6 August 2019).

5. Progressive Agriculture Safety Day. Available online: https://www.progressiveag.org/ (accessed on 6 August 2019).

6. U.S. Department of Health and Human Services (HHS). Community Partners for Healthy Farming; Office of Extramural Research, National Institutes of Health: Bethesda, MD, USA, 2003.

7. Issa, S.F.; Field, W.E.; Hamm, K.; Cheng, Y.H.; Roberts, M.; Riedel, S. Summarization of injury and fatality factors involving children and youth in grain storage and handling incidents. J. Agric. Saf. Health 2016, 22, 33-45. [PubMed]

8. National Institute for Occupational Safety and Health (NIOSH). Tractor Risk Abatement and Control: The Policy Conference; Iowa's Center for Agricultural Safety and Health, the University of Iowa: Iowa City, IA, USA, 1997.

9. Petrea, R. Using History and Accomplishments to Plan for the Future: A Summary of 15 Years in Agricultural Safety and Health and Action Steps for Future Directions; Agricultural Safety and Health Network: Urbana, IL, USA, 2003.

10. National Institute of Food and Agriculture (NIFA). National Land Grant Research and Extension Agenda for Agricultural Safety and Health, North Central Regional Association; Committee on Agricultural Safety and Health Research and Extension: East Lansing, MI, USA, 2003.

11. Sassenrath, G.; Heilman, P.; Luschei, E.; Bennett, G.; Fitzgerald, G.; Klesius, P.; Tracy, W.; Williford, J.R.; Zimba, P.V. Technology, complexity and change in agricultural production systems. Renew. Agric. Food Syst. 2008, 23, 285-295. [CrossRef]

12. Lan, Y.; Shengde, C.; Fritz, B. Current status and future trends of precision agricultural aviation technologies. Int. J. Agric. Biol. Eng. 2017, 3, 1-17.

13. USDA. ERS: Agricultural Productivity in the U.S. Available online: https://www.ers.usda.gov/data-products/ agricultural-productivity-in-the-us/ (accessed on 6 August 2019). 
14. Stueland, D.; Lee, B.; Layde, P.M. Surveillance of agricultural injuries in central Wisconsin: Epidemiologic characteristics. JRH 2008, 7, 63-72. [CrossRef]

15. Cogbill, T.; Busch, J. The spectrum of agricultural trauma. J. Emerg. Med. 1985, 3, 205-210. [CrossRef]

16. National Children's Center for Rural and Agricultural Health (NCCRAH). Agricultural Safety Brochure; NCCRAH: Marshfield, WI, USA, 2019.

17. National Institute for Occupational Safety and Health (NIOSH). 2019 Fact Sheet Childhood Agricultural Injuries in the U.S.; National Children's Center for Rural and Agricultural Health and Safety, Marshfield Clinic: Marshfield, WI, USA, 2019.

18. Jones, P.; Nelson, J.; Pirozzoli, H. The national Ag safety disc: A database of agricultural health, safety, and injury prevention educational materials. J. Agric Saf. Health 1995, 1, 7-15. [CrossRef]

19. U.S. Environmental Protection Agency (EPA). National Strategies for Health Care Providers: Pesticide Initiative Implementation Plan; The National Environmental Education and Training Foundation: Washington, DC, USA, 2002.

20. Purdue University. Gearing Up for Safety. Available online: https://extension.psu.edu/gearing-up-for-safety (accessed on 6 August 2019).

21. Ohio State University Extension. Safety. Available online: https://ohioline.osu.edu/tags/safety (accessed on 6 August 2019).

22. USDA; NIFA. Safety in Agriculture for Youth: Maintaining a National Clearinghouse. Available online: https:/portal.nifa.usda.gov/web/crisprojectpages/1013773-safety-in-agriculture-for-youthmaintaining-a-national-clearinghouse.html (accessed on 6 August 2019).

23. Journal of Agriculture Safety and Health. Available online: https://www.asabe.org/JASH (accessed on 6 August 2019).

24. International Society for Agricultural Safety and Health (ISASH). Available online: https://isash.org (accessed on 6 August 2019).

25. National Education Center for Agricultural Safety. Available online: https://www.necasag.org/ (accessed on 6 August 2019).

26. Occupational Safety and Health Administration (OSHA). Duties of Employers and Employees; OSHA Publ. No. 29 USC 654 Section 5; OSHA: Washington, DC, USA, 1970.

27. Occupational Safety and Health Administration (OSHA). Occupational Safety and Health Standards for Agriculture; OSHA Publ. No. 29 CFR 1928; OSHA: Washington, DC, USA, 1975.

28. Occupational Safety and Health Administration (OSHA). Permit-Required Confined Spaces; OSHA Publ. No. 29 CFR 1910.146; OSHA: Washington, DC, USA, 1974.

29. Occupational Safety and Health Administration (OSHA). Occupational Safety and Health Standards; OSHA Publ. No. 29 CFR 1910; OSHA: Washington, DC, USA, 1974.

30. Occupational Safety and Health Administration (OSHA). Safety and Health Regulations for Construction; OSHA Publ. No. 29 CFR 1926; OSHA: Washington, DC, USA, 1979.

31. Occupational Safety and Health Administration (OSHA). Safety Standard for Walk-Behind Power Lawn Mowers; OSHA Publ. No. 16 CFR 1205; OSHA: Washington, DC, USA, 1979.

32. Runyan, J. Summary of Federal Laws and Regulations Affecting Agricultural Employers; Economic Research Service, US Department of Agriculture: Washington, DC, USA, 2000.

33. American Society of Agricultural and Biological Engineers (ASABE). Safety for Agricultural Field Equipment; Pub No. ANSI/ASAE S318.18; ASABE: St. Joseph, MO, USA, 2017.

34. American Society of Agricultural and Biological Engineers (ASABE). Safety for Farmstead Equipment; Pub No. ANSI/ASAE S354.7; ASABE: St. Joseph, MO, USA, 2018.

35. American Society of Agricultural and Biological Engineers (ASABE). Tractors and Machinery for Agriculture and Forestry - Guards for Power Take-Off (PTO) Drive-Shafts—Strength and Wear Tests and Acceptance Criteria; Pub No. ANSI/ASABE AD5674:2004; ASABE: St. Joseph, MO, USA, 2015.

36. American Society of Agricultural and Biological Engineers (ASABE). Agricultural Machinery-Guards for Moving Parts of Power Transmission-Guard Opening without Tool; Pub No. ASABE/ISO TS 28924:2007; ASABE: St. Joseph, MO, USA, 2003.

37. American Society of Agricultural and Biological Engineers (ASABE). Safety Signs; Pub No. ANSI/ASABE AD11684:1995; ASABE: St. Joseph, MO, USA, 2011. 
38. American Society of Agricultural and Biological Engineers (ASABE). Roll-Over Protective Structures (ROPS) for Compact Utility Tractors; Pub No. ANSI/ASAE S478.1; ASABE: St. Joseph, MO, USA, 2016.

39. American Society of Agricultural and Biological Engineers (ASABE). Rollover Protective Structures (ROPS) for Wheeled Agricultural Tractors; Pub No. SAE J1194; ASABE: St. Joseph, MO, USA, 2016.

40. American Society of Agricultural and Biological Engineers (ASABE). Roll-Over Protective Structures (ROPS) for Wheeled Agricultural Tractors; Pub No. SAE J2194; ASABE: St. Joseph, MO, USA, 2016.

41. American Society of Agricultural and Biological Engineers (ASABE). Overhead Protection for Agricultural Tractors; Pub No. SAE J167; ASABE: St. Joseph, MO, USA, 2017.

42. American Society of Agricultural and Biological Engineers (ASABE). Safety Practices for Agricultural Front-End Loaders; Pub No. ANSI/ASAE S355.5; ASABE: St. Joseph, MO, USA, 2015.

43. American Society of Agricultural and Biological Engineers (ASABE). Safety for Portable Agricultural Auger Conveying Equipment; Pub No. ASAE S361.3; ASABE: St. Joseph, MO, USA, 2015.

44. American Society of Agricultural and Biological Engineers (ASABE). Grain Bin Access Design Safety; Pub No. ANSI/ASABE S624; ASABE: St. Joseph, MO, USA, 2018.

45. National Agricultural Statistical Service (NASS). Quick Stats. Available online: https://quickstats.nass.usda. gov/ (accessed on 6 August 2019).

46. Farm Labor (NASS). Available online: https://usda.library.cornell.edu/concern/publications/x920fw89s? locale $=$ en\#release-items (accessed on 6 August 2019).

47. Farms and Land in Farms (NASS). Available online: https://usda.library.cornell.edu/concern/publications/ 5712m6524? locale=en\#release-items (accessed on 6 August 2019).

48. USDA. ERS: Agricultural Productivity in the U.S.-Methods. Available online: https://www.ers.usda.gov/ data-products/agricultural-productivity-in-the-us/methods/ (accessed on 6 August 2019).

49. Myers, J.R.; Hendricks, K.J. Agricultural tractor overturn deaths: Assessment of trends and risk factors. Am. J. Ind. Med. 2010, 53, 662-672. [CrossRef] [PubMed]

50. Issa, S.F.; Nour, M.M.; Field, W.E. Utilization and effectiveness of harnesses and lifelines in grain entrapment incidents: Preliminary analysis. J. Agric. Saf. Health 2018, 24, 59-72. [CrossRef] [PubMed]

51. Leigh, J.; Marcin, J.; Miller, T. An estimate of the U.S. government's undercount of nonfatal occupational injuries. J. Occup. Environ. Med. 2004, 46, 10-18. [CrossRef] [PubMed]

(C) 2019 by the authors. Licensee MDPI, Basel, Switzerland. This article is an open access article distributed under the terms and conditions of the Creative Commons Attribution (CC BY) license (http://creativecommons.org/licenses/by/4.0/). 